\title{
DRIVING WITH CARDIOVASCULAR DISEASE: THE IMPACT OF IMPLANTABLE CARDIOVERTER DEFIBRILLATORS ON DRIVER SAFETY
}

\author{
Jessica R. Williams \& Stephen J. Tregear \\ MANILA Consulting Group, Inc. \\ McLean, Virginia, USA \\ Email: jwilliams@manilaconsulting.net
}

\begin{abstract}
Summary: Cardiovascular disease (CVD) is the leading cause of death in the United States. With America's workforce rapidly aging, more attention is being placed on CVD and its treatment among employees in safety sensitive occupations, such as the transportation industry. Implantable cardioverter defibrillators (ICDs) are increasingly being used to treat certain cardiovascular conditions, but despite the fact that they are effective in preventing sudden death from cardiac arrhythmia, there is concern about allowing individuals with an ICD to drive. A systematic review and meta-analysis was conducted to examine the health and safety impacts ICDs on driving. We considered data pertaining to four outcomes among individuals with an ICD: crash rate, the occurrence of sudden death while driving, the occurrence of syncope while driving, and the occurrence of at least one shock from their ICD while driving. Currently, the impact of an ICD on driver safety cannot be determined. Our assessments of the evidence pertaining to crash rates and sudden incapacitation while driving were inconclusive. Our results do indicate, however, that some individuals with an ICD will experience an inappropriate ICD discharge while driving (Strength of Evidence Rating: Strong). Experiencing such a discharge while driving is a potential hazard to driver safety. Quantitative assessment of the available data suggests that approximately $6.3 \%$ (95\% CI: 4.7\%-8.4\%) of all individuals with an ICD who drive will experience a discharge while driving. These findings have potential implications for regulatory agencies with responsibility for road safety; particularly those agencies that regulate safety sensitive industries.
\end{abstract}

\section{INTRODUCTION}

Driving is a complicated psychomotor performance that depends on fine coordination between the sensory and motor systems. It is influenced by factors such as arousal, perception, learning, memory, attention, concentration, emotion, reflex speed, time estimation, auditory and visual functions, decision making and personality. Safe driving requires skills to maintain effective and reliable control of vehicles, the capacity to respond to the road, traffic, and other external clues, and the ability to follow the "rules of the road". Many health conditions exist which have the potential to impair perception, cognition (including alertness, attitude to risk, and recall) and/or motor function and, as a result, can make driving less safe.

Cardiovascular disease (CVD) is the leading cause of death in the United States, accounting for approximately 1 out of every 2.8 deaths (American Heart Association, 2008). In America's aging workforce, more attention is being placed on the implications of CVD and its treatment among employees in safety sensitive occupations, such as the transportation industry. Cardiac 
arrhythmia is a type of CVD described as any change in heartbeat rhythm from the normal sequence of electrical impulses in the heart (AHA, 2006). Implantable Cardioverter Defibrillators (ICDs) are increasingly being used to treat life-threatening arrhythmias. An ICD is a battery-powered, fully implantable device consisting of the device and one or more leads. These leads monitor heart rhythm and have the capacity to deliver an electrical shock to restore normal sinus rhythm when potentially life-threatening ventricular arrhythmias are detected.

Despite the fact that ICDs have been shown to be effective in preventing sudden death resulting from cardiac arrhythmia, there is legitimate concern about the consequences of allowing individuals with an ICD to drive (Epstein et al., 2008). These concerns include the following: 1) ICDs, while effective, do not completely eliminate the risk for sudden cardiac death (SCD); 2) even the rapid intervention of an ICD following the onset of an arrhythmia may not be enough to protect against driving impairment since sudden incapacitation resulting from syncope may still occur; 3) ICD discharges, whether appropriate or not, may startle or temporarily incapacitate the patient and thereby disrupt safe motor vehicle operation.

The purpose of this study was to answer a critical question about the health and safety impacts of ICDs on driving; namely, should individuals with an ICD be allowed to drive? The specific objectives were to: 1) assess the risk of motor vehicle crash among individuals following the implantation of an ICD; 2) determine the proportion of individuals with an ICD who experience syncope and sudden death while driving; and 3) examine the number of individuals who received at least one shock from their ICD while driving.

\section{METHODS}

In order to address our objectives, a systematic review of the literature was conducted (Treadwell et al., 2006). We synthesized the available data from published studies that examined the incidence of sudden death and sudden incapacitation due to syncope among drivers with an ICD, and studies that examined the occurrence of ICD discharge during driving. Formal a priori criteria for article retrieval and inclusion consisted of: 1) English language publications, 2) fulllength articles, 3) enrolled $\geq 10$ subjects, 4) subjects must be $\geq 18$ years, 5) article must describe a study that assessed the occurrence of crash, SCD, sudden incapacitation due to syncope, or ICD discharge during driving. Case reports and series of carefully selected patients chosen to demonstrate a particular point were excluded.

Sensitive search strategies, developed and refined by an information specialist, were applied to seven electronic databases (Medline, PubMed (pre Medline), EMBASE, PSYCHInfo, CINAHL, TRIS, and the Cochrane library). Additional hand searches of the published literature (i.e., bibliographies of identified relevant articles) and "gray literature" resources (e.g., Web searches) were also performed. The quality of all included studies was determined using the ECRI Quality Scale VI, which was designed specifically for the assessment of the validity of surveys. Fixedeffects meta-analysis was used to pool data from different studies. Sensitivity analyses, aimed at testing the robustness of our findings, included the use of cumulative fixed-effects meta-analysis. 


\section{RESULTS}

\section{Identification of Evidence Base}

Our searches identified a total of 427 articles that appeared relevant to the purpose of this study. Following application of the retrieval criteria, 69 full-length articles retrieved and read in full. Of these articles, 7 were found to meet our inclusion criteria.

\section{Description of Evidence Base}

All seven studies that met our inclusion criteria employed a survey design. Only two studies included a comparison group (Akiyama et al., 2001; Conti et al., 1997) and only one study considered driving exposure (Conti et al., 1997). The quality assessment scores for each of these seven articles were "Low", with the exception of Curtis et al. (1995), which was deemed to be of "Extremely Low" quality. "Extremely Low" quality studies are considered to be fatally flawed, and therefore, we did not consider outcome data from this study any further in this report. The primary reasons for the "Low" quality rating of the other studies include the reliance on surveys to collect data and the high non-response rates found in some of the studies. With regards to generalizability, subjects in this small group of studies were generally male, but older than would be expected for the average CMV driver. Driving distances were not addressed in these studies; however, a number of other papers indicated that most ICD recipients discontinued driving, drove fewer miles, or modified their driving habits in some way by not driving in inclement weather, avoiding peak traffic and engaging in similar precautions.

\section{Motor Vehicle Crash among Individuals with ICD}

Four of the six included studies presented data on the number or frequency of crashes that occurred among individuals with an ICD. These data are summarized in Table 1.

Table 1. Crash Data Extracted from Included ICD Studies

\begin{tabular}{|l|c|c|c|c|c|c|}
\hline Reference & Year & $\begin{array}{c}\text { Number } \\
\text { of } \\
\text { Drivers }\end{array}$ & $\begin{array}{c}\text { Mean FUT } \pm \text { SD } \\
\text { (months) }\end{array}$ & $\begin{array}{c}\text { Number Who } \\
\text { Crashed at Least } \\
\text { Once (\%) }\end{array}$ & $\begin{array}{c}\text { Number of Crashes } \\
\text { at Fault (\%) }\end{array}$ & $\begin{array}{c}\text { Number of Total } \\
\text { Crashes Related to } \\
\text { CVD (\%) }\end{array}$ \\
\hline \hline Trappe et al. & 1998 & 171 & $38 \pm 24$ & $11(6.4)$ & $1(9.1)$ & $0(0.0)$ \\
\hline Conti et al. & 1997 & 73 & 5.3 years $\pm \mathrm{NR}$ & $0(0.0)$ & $0(0.0)$ & $0(0.0)$ \\
\hline Finch et al. & 1997 & 81 & $21.6 \pm \mathrm{NR}$ & $0(0.0)$ & $0.0)$ & $0(0.0)$ \\
\hline Finch et al. & 1993 & 28 & $\begin{array}{c}\text { NR } \pm \mathrm{NR} \\
\text { Range: } 1 \text { to } 36\end{array}$ & $0(0.0)$ & $0.0)$ & $0(0.0)$ \\
\hline
\end{tabular}

* Investigators did not present crash data for two groups separately. Rather they reported on the overall number of crashes experienced by individuals treated with an ICD and pharmacotherapy and merely noted that crash rate was lower in ICD group.

CVD Cardiovascular disease.

ICD Implantable cardioverter defibrillator.

NR Not reported.

SD Standard deviation. 
Crashes reportedly occurred in only one of the four included studies. Trappe et al. (1998) noted that 11 individuals enrolled in their study experienced at least one crash during follow-up. Of these, only one was determined to be the fault of the driver, and none of the crashes were the consequence of either CVD or an event associated with the implanted ICD. No crashes were reported to have occurred among the individuals enrolled in the remaining three studies. This may be the combined consequence of the small size of these studies and their short follow-up times. In order to determine a reliable estimate of the crash rate associated with ICDs, studies with far larger sample sizes and longer follow-up times will need to be performed.

\section{Occurrence of Syncope and Sudden Death while Driving}

Three of the six included studies reported on the occurrence of syncope and sudden death while an individual with an ICD was driving. Relevant data from these studies are summarized in Table 2 .

Table 2. Number of Individuals who Experienced Syncope or SCD while Driving

\begin{tabular}{|l|c|c|c|c|c|c|c|c|}
\hline Reference & Year & $\mathbf{N}=\begin{array}{c}\text { Number } \\
\text { of } \\
\text { Drivers }\end{array}$ & $\begin{array}{c}\text { Mean FUT } \\
\pm \text { SD }\end{array}$ & $\begin{array}{c}\text { Number who } \\
\text { Experienced } \\
\text { Syncope (\%) }\end{array}$ & $\begin{array}{c}\text { Number } \\
\text { Who } \\
\text { Experienced } \\
\text { Syncope } \\
\text { While } \\
\text { Driving (\%) }\end{array}$ & $\begin{array}{c}\text { Number } \\
\text { Whomber } \\
\text { Eho } \\
\text { Eudden- } \\
\text { Surienced } \\
\text { Cardiac } \\
\text { Death (\%) }\end{array}$ & $\begin{array}{c}\text { Experienced } \\
\text { Sudden- } \\
\text { Cardiac } \\
\text { Death While } \\
\text { Driving (\%) }\end{array}$ \\
\hline \hline Trappe et al. & 1998 & 241 & 171 & $\begin{array}{c}\text { Range: }<1 \\
\text { to124 }\end{array}$ & $15(5.2)$ & $0(0.0)$ & $8(2.8)$ & $0(0.0)$ \\
\hline Finch et al. & 1997 & 105 & 81 & $21.6 \pm N R$ & $1(1.2)$ & $0(0.0)$ & $0(0.0)$ & $0(0.0)$ \\
\hline Finch et al. & 1993 & 40 & 28 & $\begin{array}{c}\text { Range: } 1 \text { to } \\
36\end{array}$ & $0(0.0)$ & $0(0.0)$ & $0(0.0)$ & $0(0.0)$ \\
\hline
\end{tabular}

FUT Follow-up time.

NR Not reported.

SCD Sudden cardiac death.

SD Standard deviation.

None of the individuals enrolled in the three included studies above experienced syncope or SCD while driving.

\section{Occurrence of ICD Discharge while Driving}

All six included studies reported on the occurrence of ICD discharge during driving. Relevant data from these studies are summarized in Table 3.

In order to obtain an estimate of the expected proportion of individuals with an ICD who might be expected to experience at least one ICD discharge shock during follow-up, we pooled data from all six studies using meta-analysis. Despite the fact that follow-up times varied across studies, homogeneity testing found that the ICD discharge data were consistent $(\mathrm{Q}=6.516, P=$ $\left.0.259 ; \mathrm{I}^{2}=23.268\right)$. Because these data were homogeneous, we pooled them using a fixed-effects 
Table 3. Number of Individuals with ICD who Experience Shock while Driving

\begin{tabular}{|l|c|c|c|c|c|c|}
\hline Reference & Year & N $=$ & $\begin{array}{c}\text { Number } \\
\text { of } \\
\text { Drivers }\end{array}$ & Mean FUT \pm SD & $\begin{array}{c}\text { Number Who } \\
\text { Experienced Shock } \\
\text { During Follow-up (\%) }\end{array}$ & $\begin{array}{c}\text { Number Who } \\
\text { Experienced Shock } \\
\text { While Driving (\%) }\end{array}$ \\
\hline \hline $\begin{array}{l}\text { Akiyama et } \\
\text { al. }\end{array}$ & 2001 & 328 & 295 & $\begin{array}{c}35 \pm \mathrm{NR} \\
\text { Range: NR }\end{array}$ & $24(8.1)$ \\
\hline $\begin{array}{l}\text { Trappe et } \\
\text { al. }\end{array}$ & 1998 & 241 & 171 & $\begin{array}{c}38 \pm 28 \\
\text { Range: }<1 \text { to124 }\end{array}$ & $224(77.0)$ & $8(4.7)$ \\
\hline Conti et al. & 1997 & 85 & 73 & $\begin{array}{c}5.3 \text { years } \pm \text { NR } \\
\text { Range: NR }\end{array}$ & $52(63.4)$ & $5(0.0)^{*}$ \\
\hline Finch et al. & 1997 & 105 & 81 & $\begin{array}{c}21.6 \pm N R \\
\text { Range: NR }\end{array}$ & $3(3.7)$ \\
\hline $\begin{array}{l}\text { Craney and } \\
\text { Powers }\end{array}$ & 1995 & 97 & 72 & $\begin{array}{c}26 \pm N R \\
\text { Range: } 6 \text { to } 108\end{array}$ & $32(43.3)$ & $3(4.1)$ \\
\hline Finch et al. & 1993 & 40 & 28 & Range: 1 to 36 & $26(65.0)$ & $2(7.1)$ \\
\hline
\end{tabular}

* Discharges during previous 12 months only.

FUT Follow-up time.

ICD Implantable cardioverter defibrillator.

SD Standard deviation.

model. The results of this analysis are presented in Figure 1. According to the findings of this analysis, the number of individuals with an ICD who will experience at least one shock during driving (appropriate or inappropriate) is in the order of 6.3\% (95\% CI: 4.7-8.4\%). A series of sensitivity analyses found the findings of this analysis to be robust.

\begin{tabular}{|c|c|c|c|c|c|c|c|c|}
\hline \multirow[t]{2}{*}{$\underline{\text { Study name }}$} & \multicolumn{5}{|c|}{ Statistics for each study } & & \multicolumn{2}{|c|}{ Event rate and $95 \% \mathrm{Cl}$} \\
\hline & $\begin{array}{c}\text { Event } \\
\text { rate }\end{array}$ & $\begin{array}{c}\text { Lower } \\
\text { limit }\end{array}$ & $\begin{array}{c}\text { Upper } \\
\text { limit }\end{array}$ & Z-Value & p-Value & & & \\
\hline Akayama & 0.081 & 0.055 & 0.119 & -11.382 & 0.000 & & & -- \\
\hline Trappe & 0.047 & 0.024 & 0.091 & -8.324 & 0.000 & & & $\rightarrow$ \\
\hline Conti & 0.007 & 0.000 & 0.099 & -3.517 & 0.000 & & & \\
\hline Finch (1997) & 0.037 & 0.012 & 0.109 & -5.538 & 0.000 & & & \\
\hline Craney and Powers & 0.042 & 0.014 & 0.121 & -5.316 & 0.000 & & & \\
\hline \multirow[t]{3}{*}{ Finch } & 0.071 & 0.018 & 0.245 & -3.495 & 0.000 & & & \\
\hline & 0.063 & 0.047 & 0.084 & -16.608 & 0.000 & & & - \\
\hline & & & & & & -0.25 & -0.13 & 0.00 \\
\hline
\end{tabular}

Figure 1. Proportion of Individuals who Experienced ICD Discharge during Driving

\section{Time to First ICD Discharge while Driving}

None of the included studies reported on the time to first ICD discharge during driving. However, Trappe et al. (1998) reported on the time interval from ICD implantation to first discharge among drivers and non-drivers. No significant differences among drivers and nondrivers in the interval postimplant to first discharge were observed. The mean time to first ICD 
discharge was 9 months (SD: 12) and among non-drivers 9 months (SD: 10). First ICD discharge was delivered within the first 6 months postimplant in 52\% of drivers and 53\% of non-drivers.

\section{Risk Factors for ICD Discharge while Driving}

In an attempt to identify individuals who are at most risk for an ICD discharge during driving, Trappe et al. (1998) performed a multivariate analysis. This analysis included data about age, gender, underlying disease, LVEF, spontaneous arrhythmias before ICD implant, induced arrhythmias during the electrophysiology study, defibrillation threshold, antiarrhythmic drugs, other drugs (i.e., digitalis, diuretics, ACE inhibitors, nitrates), and types of implanted devices (i.e., monophasic or biphasic waveform shocks, ICD with or without antitachycardia pacing modalities). These investigators were unable to identify any characteristics that could be used to identify individuals who are at most risk for an ICD discharge during driving. None of the remaining included studies attempted to identify which individuals with an ICD presented the most risk for ICD discharge during driving.

\section{DISCUSSION}

Our assessments of the evidence pertaining to crash rates and sudden incapacitation while driving were inconclusive. None of the included studies compared crash rates occurring among individuals with an ICD to crash rates among individuals without CVD. Consequently, it is not possible to determine whether individuals with an ICD are at increased risk for a motor vehicle crash. In the three studies that examined the occurrence of syncope and sudden death while an individual with an ICD was driving, no study participants experienced syncope or SCD while driving. Given the fact that syncope and sudden-death while driving have to be considered as rare events, the fact that no cases were observed in the three included studies cannot be considered as evidence that such events will not occur while driving.

The results of our analyses do indicate, however, that some individuals with an ICD will experience an ICD discharge while driving (Strength of Evidence Rating: Strong). Experiencing such a discharge while driving is a potential hazard to driver safety. Quantitative assessment of the available data suggests that approximately $6.3 \%$ (95\% CI: 4.7\%-8.4\%) of all individuals with an ICD who drive will experience a discharge while driving. A series of sensitivity analyses found the findings of this analysis to be robust. Despite the fact that follow-up times varied across studies, no relationship was found between follow-up time and number of discharges. This is probably due to the low event rate which, consequently, increases variance and impairs the ability to detect heterogeneity. These findings have potential implications for regulatory agencies with responsibility for road safety; particularly those agencies that regulate safety sensitive industries.

\section{ACKNOWLEDGEMENTS}

This research was performed under United States Department of Transportation contract number GS-10F-0177N/DTMC75-06-F-00039. The opinions of the authors expressed herein do not necessarily state or reflect those of the United States Government. 


\section{REFERENCES}

Akiyama, T., Powell, J.L., Mitchell, L.B., Ehlert, F.A., \& Baessler, C. (2001). Antiarrhythmics versus implantable defibrillators investigators. Resumption of driving after life-threatening ventricular tachyarrhythmia. New England Journal of Medicine, 345(6), 391-397.

American Heart Association. (2008). Cardiovascular Disease Statistics. Retrieved on November20, 2008. Available at: http://www.americanheart.org/presenter.jhtml?identifier $=4478$

American Heart Association. (2006). What are arrhythmias? Retrieved on October 11, 2006. Available at: http://www.americanheart.org/presenter.jhtml?identifier $=560$

Conti, J. B., Woodard, D.A., Tucker, K.J., Bryant, B., King, L.C., \& Curtis, A.B. (1997). Modification of patient driving behavior after implantation of a cardioverter defibrillator. Pacing and Clinical Electrophysiology, 20(9 Pt 1), 2200-2204.

Craney, J.M. \& Powers, M.T. (1995). Factors related to driving in persons with an implantable cardioverter defibrillator. Progress in Cardiovascular Nursing, 10(3), 12-17.

Curtis, A.B., Conti, J.B., Tucker, K.J., Kubilis, P.S., Reilly, R.E., \& Woodard, D.A. Motor vehicle accidents in patients with an implantable cardioverter-defibrillator. Journal of the American College of Cardiology, 26(1), 180-184.

Epstein, A.E., DiMarco, J.P., Ellenbogen, K.A., Estes, M., Freeman, R.A., Gettes, L.S., et al. (2008). ACC/AHA/HRS 2008 Guidelines for device-based therapy of cardiac rhythm abnormalities: A report of the American College of Cardiology/American Heart Association Task Force on Practice Guidelines. Circulation, 117, e350-e408.

Finch, N.J., Leman, R.B., Kratz, J.M., \& Gillette, P.C. (1993). Driving safety among patients with automatic implantable cardioverter defibrillators. Journal of the American Medical Association, 270(13), 1587-1588.

Finch, N.J., Sneed, N.V., Leman, R.B., \& Watson, J. (1997). Driving with an internal defibrillator: legal, ethical, and quality-of-life issues. Journal of Cardiovascular Nursing, 11(2), 58-67.

Trappe, H.J., Wenzlaff, P., \& Grellman, G. (1998). Should patients with implantable cardioverter defibrillators be allowed to drive? Observations in 291 patients from a single center over an 11-year period. Journal of Interventional Cardiac Electrophysiology, 2(2), 193-201.

Treadwell, J.T., Tregear, S.J., Reston, J.T., \& Turkelson, C. M. A system for rating the stability and strength of medical evidence. BMC Medical Research Methodology, 19, 6-52. Also available: http://www.biomedcentral.com/1471-2288/6/52.

United States Department of Labor, Bureau of Labor Statistics. (2008). National census of fatal occupational injuries. Retrieved on November 20, 2008. Available at: http://www.bls.gov/iif/oshcfoil.htm 